\title{
RELAÇÕES ENTRE AQUISIÇÃO DA PERCEPÇÃO AUDITIVA E APRENDIZAGEM DA ORTOGRAFIA: CONSOANTES SOANTES EM QUESTÃO
}

\author{
Lourenço Chacon \\ Universidade Estadual Paulista \\ Marília, São Paulo, Brasil \\ São José do Rio Preto, São Paulo, Brasil \\ Suellen Vaz \\ Universidade Estadual Paulista \\ Marília, São Paulo, Brasil
}

Resumo: Foram comparadas relações entre a aquisição da percepção-auditiva e a aprendizagem da ortografia de consoantes soantes em crianças das duas primeiras séries do ensino fundamental. A comparação foi baseada num procedimento de identificação e de escrita de um mesmo conjunto de palavras que apresentavam contrastes fonológicos entre si. Quanto aos resultados, verificou-se: (1) gradiência na aquisição de subclasses no interior de uma grande classe; (2) correspondências e não correspondências entre os dois tipos de tarefa; (3) mais ajustes na ortografia e mais desajustes na percepção-auditiva com o aumento da escolarização. Esse conjunto de resultados aponta, portanto, para a complexidade das relações entre a aquisição da percepçãoauditiva e a aquisição da ortografia, já que, uma vez em contato, seu percurso conjunto ao mesmo tempo promove enlaces e desenlaces entre elas.

Palavras-chave: Aquisição da escrita. Percepção-auditiva. Ortografia.

\footnotetext{
* Professor da UNESP, campi de Marília e de São José do Rio Preto. Bolsista Pq/CNPq. Doutor em Linguística pela Universidade Estadual de Campinas - UNICAMP. Email: lourencochacon@yahoo.com.br

** Mestranda do Programa de Pós-graduação em Fonoaudiologia (UNIESP), campus de Marília. Bolsista CAPES. Email: suellenvazz@gmail.com
} 


\section{INTRODUÇÃO}

Há quase 30 anos, os pesquisadores Maria Bernadete Marques Abaurre e Luiz Carlos Cagliari iniciaram a publicação de resultados de suas investigações sobre as relações entre características fonético-fonológicas da língua e aspectos da aquisição da escrita, como a ortografia e a segmentação de palavras. O cunho inovador dessas investigações pode ser constatado, sobretudo, em Abaurre et al. (1985), em Cagliari (1986) e em Abaurre (1986, 1988). Resultados posteriores dessas investigações foram publicados em outros trabalhos, como, por exemplo: Abaurre (1994, 1999, 2001); Abaurre e Abaurre (1999), e Cagliari (1992, 1998, 2001, 2002, 2004).

Inspirados nessas investigações pioneiras, pesquisadores brasileiros situados no campo dos estudos linguísticos ${ }^{1}$ vêm produzindo importantes reflexões sobre características fonético-fonológicas da língua e aspectos variados da aquisição e do desenvolvimento da escrita. A título de exemplo, serão destacadas três vertentes de estudos que podem ser situados na tradição instaurada pelas primeiras investigações de Abaurre e de Cagliari.

A primeira vertente (a que se tem mostrado como mais produtiva, no sentido de que abarca o maior conjunto de publicações) é aquela que se volta para as relações entre constituintes prosódicos - tais como postulados por Nespor e Vogel (1986) - e segmentações não convencionais de palavras. Nessa vertente, têm sido publicados resultados de investigações sobre a escrita nas séries iniciais do Ensino Fundamental - Cunha (2004, 2010); Cunha, Miranda (2007, 2009); Capristano (2004, 2007, 2010); Serra, Tenani, Chacon (2006); Chacon (2004a, 2005, 2006) -, nas séries finais desse mesmo Ensino - Tenani (2010); Tenani, Paranhos (2011) -; e na alfabetização de jovens e adultos - Tenani (2004, 2008); Ferreira (2010).

A segunda vertente caracteriza um conjunto de trabalhos sobre as relações entre constituintes prosódicos e presença/ausência de sinais de pontuação. Ilustram essa vertente trabalhos de Chacon (1999, 2004b) e Soncin (2010).

1 Direta ou indiretamente, reflexões de Abaurre e de Cagliari podem ser localizadas, também, num conjunto de trabalhos que (não majoritariamente) se desenvolvem no campo da Fonoaudiologia brasileira. A título de exemplo, destacamos Kristensen e Freire (2001), Perrotta (2002), Massi (2004), Barcellos e Freire (2005), Massi et al. (2008). 
Uma terceira vertente, por fim, investiga as relações entre a organização interna da sílaba e a ortografia. Representam essa vertente trabalhos como os de Miranda et al. (2005), Miranda (2008), Chacon (2008), Chacon e Berti (2008), Adamoli e Miranda (2009), Miranda e Matzenauer (2010), Cardoso et al. (2010), Berti et al. (2010), Komesu e Tenani (2010), Teixeira et al. (2011), Chacon et al. (2011), Amaral et al. (2011), Tenani e Reis (2011) e Campos et al. (2011).

Quanto a essa terceira vertente, uma observação pontual pode ser feita a propósito de resultados expostos em Berti et al. (2010), Chacon et al. (2011) e Amaral et al. (2011) - pesquisadores e estudantes vinculados ao Grupo de Pesquisa Estudos sobre a linguagem (GPEL/CNPq). Essa observação deve-se ao fato de que, ao buscarem hipóteses explicativas para flutuações ortográficas na aquisição da escrita, os autores desses trabalhos chamam a atenção para aspectos perceptuais/auditivos possivelmente envolvidos nessas flutuações. No entanto, trata-se de relação (ortografia/percepção-auditiva) sugerida, mas não estudada pelos autores.

Bem recentemente, a relação entre a aquisição da percepção-auditiva e a aquisição da escrita começou a ser investigada no interior do GPEL, como ilustram os trabalhos de Schier (2012), de Vaz (2012) e de Schier, Berti e Chacon (2013). O primeiro e o terceiro deles voltaram-se para essa relação em consoantes fricativas. O segundo, ainda em andamento, motivou-nos a expor e a aprofundar a discussão, neste artigo, de seus primeiros resultados - sobre a relação entre a aquisição da percepçãoauditiva e a aquisição da ortografia de consoantes soantes. Contribuir para avanços na investigação dessa relação é, portanto, a principal expectativa com que desenvolvemos este estudo.

\section{OBJETIVOS}

O desenvolvimento do presente artigo foi norteado pelos seguintes objetivos: (a) comparar a acurácia perceptual-auditiva e a acurácia ortográfica de consoantes soantes em crianças do $1^{\circ}$ e do $2^{\circ}$ ano do ensino fundamental; e (b) comparar a identificação dos contrastes entre essas consoantes que se mostrarem como mais facilmente (ou mais dificilmente) percebidos e registrados ortograficamente pelas mesmas crianças. 


\section{MATERIAL E MÉTODOS \\ 3.1 PARTICIPANTES}

Participaram deste estudo 53 crianças de duas turmas do $1^{\circ}$ ano (turmas B e C) e 48 crianças de duas do $2^{\circ}$ ano (turmas B e C) de uma escola estadual de ensino fundamental de um município do interior paulista.

3.2 MATERIAL

Foi utilizado o Instrumento de Avaliação da Percepção de Fala PERCEFAL - de Berti (2011), com o uso do software PERCEVAL (Perception Evaluation Auditive \& Visuelle) (ANDRÉ et al., 2009).

$\mathrm{O}$ referido instrumento foi elaborado para avaliar o desempenho perceptual- auditivo de crianças a partir dos quatro anos de idade, com base em uma tarefa de identificação (também chamada de tarefa de escolha forçada) envolvendo os contrastes fonológicos do Português Brasileiro (doravante PB) em onset silábico. Nesse instrumento estão envolvidas, preferencialmente, palavras dissilábicas paroxítonas, contendo todos os 19 fonemas consonantais do PB na posição acentuada.

A seleção das palavras foi realizada de acordo com os seguintes critérios: (1) contrastarem os fonemas do PB de modo a comporem pares mínimos de palavras; (2) serem passíveis de representação por meio de gravuras; (3) pertencerem ao vocabulário infantil; e (4) pertencerem ao rol de palavras elencadas em um estudo prévio (MOTA, 2001).

O PERCEFAL é composto por um subconjunto de quatro experimentos: (a) PERCivogais (que avalia a identificação do contraste fônico entre vogais tônicas); (b) PERCocl (que avalia a identificação do contraste fônico entre oclusivas); (c) PERCifric (que avalia a identificação do contraste fônico entre fricativas); e (d) PERCison (que avalia a identificação do contraste fônico entre soantes). Em função dos objetivos do presente artigo, foi utilizado apenas o PERCison.

$\mathrm{Na}$ elaboração do PERCison foi arrolado um total de 30 palavras (por análise combinatória: 6 soantes x 5 possibilidades de combinação entre elas $=30$ palavras, sendo 15 pares contrastivos). Segue-se uma síntese dessas palavras e desses pares no quadro 1 . 


\section{Quadro 1 - Pares contrastivos de soantes}

\begin{tabular}{|c|c|c|}
\hline Palavra Alvo & Palavra Contrastada & Par Contrastado \\
\hline Mata & Nata & $/ \mathrm{m} /-/ \mathrm{n} /$ \\
\hline Uma & Unha & $/ \mathrm{m} /-/ \mathrm{n} /$ \\
\hline Mata & Lata & $/ \mathrm{m} /-/ 1 /$ \\
\hline Comer & Colher & $/ \mathrm{m} /-\mid \mathrm{K} /$ \\
\hline Fumo & Furo & $/ \mathrm{m} /-/ \mathrm{s} /$ \\
\hline Nata & Mata & $/ \mathrm{n} /-/ \mathrm{m} /$ \\
\hline Sono & Sonho & $/ \mathrm{n} /-/ \mathrm{n} /$ \\
\hline Nata & Lata & $/ \mathrm{n} /-/ 1 /$ \\
\hline Fina & Filha & $/ \mathrm{n} /-/ \Lambda /$ \\
\hline Caneta & Careta & $/ \mathrm{n} /-/ \mathrm{s} /$ \\
\hline Unha & Uma & $/ \mathrm{n} /-/ \mathrm{m} /$ \\
\hline Sonho & Sono & $/ \mathrm{n} /-/ \mathrm{n} /$ \\
\hline Punho & Pulo & $/ \mathrm{n} /-/ \mathrm{l} /$ \\
\hline Pinha & Pilha & $/ \mathrm{n} /-/ \mathrm{K} /$ \\
\hline Sonho & Soro & $/ \mathrm{n} /-/ \mathrm{s} /$ \\
\hline Lata & Mata & $/ 1 /-/ \mathrm{m} /$ \\
\hline Lata & Nata & $/ 1 /-/ \mathrm{n} /$ \\
\hline Pulo & Punho & $/ 1 /-/ \mathrm{n} /$ \\
\hline Vela & Velha & $/ 1 /-/ K /$ \\
\hline Pulo & Puro & $/ 1 /-/ \mathrm{s} /$ \\
\hline Colher & Comer & $/ \mathrm{K} /-/ \mathrm{m} /$ \\
\hline Filha & Fina & $/ K /-/ \mathrm{n} /$ \\
\hline Pilha & Pinha & $/ \Lambda /-/ \mathrm{n} /$ \\
\hline Velha & Vela & $\mid \Lambda /-/ 1 /$ \\
\hline Palha & Para & $\mid \Lambda /-/ \mathrm{d} /$ \\
\hline Furo & Fumo & $/ \mathrm{r} /-/ \mathrm{m} /$ \\
\hline Careta & Caneta & $/ \mathrm{r} /-/ \mathrm{n} /$ \\
\hline Soro & Sonho & $/ \mathrm{r} /-/ \mathrm{n} /$ \\
\hline Puro & Pulo & $/ \mathrm{s} /-/ \mathrm{l} /$ \\
\hline Para & Palha & $/ \mathrm{f} /-\mid \mathrm{K} /$ \\
\hline
\end{tabular}

Definidas as palavras que comporiam o PERCison, Berti (2011) realizou a gravação das palavras selecionadas (com equipamentos de alta fidelidade) no interior de uma cabine acústica, com um adulto falante típico do PB falado na região de coleta dos dados. Foi solicitada ao adulto a produção das palavras-alvo no interior de uma frase veículo ("Fale palavra alvo pra ele"), de modo a evitar a curva ascendente característica da produção obtida por meio de repetição isolada de palavras. 
Ao término das gravações, com o auxílio do software PRAAT (BOERSMAN e WEENINK, 2009), os pares mínimos foram extraídos da frase-veículo, constituindo os inputs auditivos do experimento.

Paralelamente à edição dos arquivos de áudio, foram selecionadas gravuras correspondentes a cada palavra, a partir do site $<$ http://images.google.com.br/> de domínio público. Com o auxílio do software Paint, as imagens foram recortadas e editadas de modo a ficarem padronizadas, gerando, assim, os inputs visuais do PERCison.

Estabelecidos os inputs auditivos e visuais que integrariam o experimento, foi elaborado um script $t^{2}$ para o experimento de identificação executado pelo software PERCEVAL.

\subsection{PROCEDIMENTO EXPERIMENTAL}

O procedimento experimental de percepção proposto no PERCEFAL consiste em um teste de identificação, também designado de tarefa de escolha forçada. O referido teste é composto por três etapas distintas: reconhecimento das palavras do experimento; fase treino; e fase teste.

A etapa de reconhecimento envolve a apresentação dos inputs visual e auditivo às crianças a fim de averiguar o seu conhecimento (ou não) em relação às palavras utilizadas no experimento. Após a familiarização das crianças com os inputs do experimento, realiza-se uma sondagem, ou seja, uma verificação do conhecimento das palavras pelas crianças. Adota-se um critério de $80 \%$ de acerto para que as crianças sejam conduzidas à fase treino e, posteriormente, ao teste perceptual propriamente dito.

A fase treino é realizada automaticamente pelo software, com o intuito de garantir a compreensão da tarefa por parte dos participantes. Essa fase baseia-se na própria tarefa de identificação perceptual, mas os resultados obtidos não são computados pelo software. São aleatorizados os estímulos do experimento e selecionadas dez apresentações. Logo após, inicia-se a fase teste propriamente dita.

\footnotetext{
${ }^{2}$ A obtenção do script do experimento de identificação perceptual pode ser solicitada à autora do PERCEFAL no seguinte e-mail: berti.larissa@gmail.com.
} 
Para a tarefa de identificação, as crianças foram dispostas confortavelmente em frente à tela de um computador (contendo o software PERCEVAL) com fones KOSS acoplados aos seus ouvidos, na própria escola (em uma sala silenciosa). As crianças, individualmente, ouviram (com apresentação binaural numa intensidade de $50 \mathrm{~dB}$ aproximadamente) uma das palavras do par mínimo e, em seguida, decidiram e indicaram qual a gravura correspondente à palavra apresentada auditivamente, dentre duas possibilidades de gravuras que foram dispostas na tela do computador. Por exemplo, ao ser apresentada auditivamente à criança a palavra "vela", foram dispostas na tela do computador as gravuras correspondentes às palavras "vela" e "velha", para que o participante decidisse e indicasse, pressionando duas teclas do computador previamente combinadas, qual gravura correspondia ao estímulo auditivo apresentado.

Tanto o tempo de apresentação dos estímulos auditivo e visual quanto o tempo de resposta foram controlados e mensurados automaticamente pelo software PERCEVAL. A duração total do experimento foi de aproximadamente 15 minutos por criança.

Para a coleta do desempenho ortográfico dos mesmos pares mínimos utilizados no experimento de percepção-auditiva, inicialmente foram apresentadas para todas as crianças folhas impressas com todas as figuras do experimento em sala de aula. A seguir, solicitou-se que escrevessem, em uma linha ao lado de cada figura, o nome correspondente a cada uma delas.

\subsection{FORMA DE ANÁLISE DOS RESULTADOS}

Expõem-se os critérios de análise dos resultados relativos ao primeiro objetivo deste artigo - relembrando-o: comparar a acurácia perceptual-auditiva e a acurácia ortográfica de consoantes soantes em crianças do $1^{\circ}$ e do $2^{\circ}$ ano do ensino fundamental.

No que se refere à acurácia perceptual-auditiva, foram adotados como critérios de análise os mesmos descritos no PERCEFAL (BERTI, 2011), a saber: porcentagem de erros, de acertos e de não-respostas. Já no que se refere ao que chamamos de acurácia ortográfica, também foram adotados os mesmos critérios descritos no PERCEFAL. No entanto, foi preciso acrescentar mais um critério, em razão de, algumas vezes, a escrita 
da criança fugir completamente às convenções ortográficas, dificultando sua leitura. Com esse acréscimo, os critérios foram: porcentagem de erros, de acertos, de não respostas e de respostas não interpretáveis.

Passa-se, a seguir, aos critérios de análise dos resultados relativos ao segundo objetivo deste artigo. Relembrando-o: comparar a identificação dos contrastes entre consoantes soantes que se mostrarem como mais facilmente (ou mais dificilmente) percebidos e registrados ortograficamente pelas mesmas crianças.

Para fazer essa comparação, foi utilizada a proposta de uma matriz de confusão (MILLER; NICELY, 1955) para catalogar quantitativamente e qualitativamente os erros perceptivos cometidos pelas crianças. Destaca-se que este tipo de análise propicia informações relativas tanto aos contrastes mais, e menos, difíceis na tarefa de identificação, quanto aos padrões de erros mais recorrentes. Uma adaptação dessa matriz foi feita para a identificação dos contrastes ortográficos mais facilmente ou mais dificilmente registrados pelas crianças.

\section{EXPOSIÇÃO DOS RESULTADOS}

Para melhor exposição dos resultados finais, organizamo-los em função dos objetivos que orientaram o desenvolvimento da investigação exposta neste artigo. Com relação ao primeiro objetivo, apresentamos na tabela 1 os resultados a que chegamos à verificação da acurácia perceptualauditiva e na acurácia ortográfica.

\section{Tabela 1 - Acurácia perceptual-auditiva e ortográfica}

\begin{tabular}{|c|c|c|c|c|c|c|c|c|c|c|}
\hline \multirow[t]{2}{*}{ Ano } & \multirow[t]{2}{*}{ Turma } & \multicolumn{2}{|c|}{ Acertos } & \multicolumn{2}{|c|}{ Erros } & \multicolumn{2}{|c|}{ Não Resposta } & \multirow{2}{*}{$\frac{\mathbf{N I}^{*}}{\text { Ort. }}$} & \multicolumn{2}{|c|}{ Total } \\
\hline & & Per. & Ort. & Per. & Ort. & Per. & Ort. & & Per. & Ort. \\
\hline 1 & $\mathrm{~B}$ & 737 & 415 & 85 & 178 & 18 & 0 & 79 & 840 & 672 \\
\hline 1 & $\mathrm{C}$ & 582 & 311 & 134 & 126 & 34 & 18 & 145 & 750 & 600 \\
\hline 1 & $\mathrm{~B}$ e $\mathrm{C}$ & 1319 & 726 & 219 & 304 & 52 & 18 & 224 & 1590 & 1272 \\
\hline 2 & B & 604 & 568 & 115 & 31 & 31 & 0 & 1 & 750 & 600 \\
\hline 2 & $\mathrm{C}$ & 544 & 490 & 126 & 55 & 20 & 1 & 6 & 690 & 552 \\
\hline 2 & $\mathrm{~B}$ e $\mathrm{C}$ & 1148 & 1058 & 241 & 86 & 51 & 1 & 7 & 1440 & 1152 \\
\hline \multicolumn{2}{|c|}{ Total } & 2467 & 1784 & 460 & 390 & 103 & 19 & 231 & 3030 & 2424 \\
\hline
\end{tabular}

* NI = Dados não interpretáveis 
Seguem os resultados detalhados para o $1^{\circ}$ ano.

Gráfico 1 - Percentual de acertos no $1^{\circ}$ ano

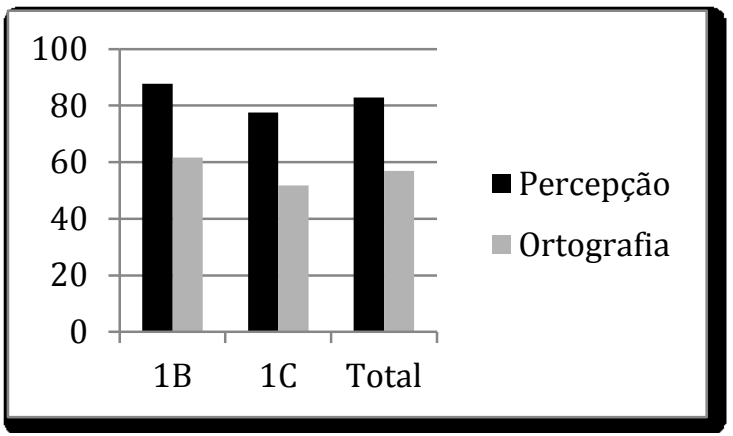

Gráfico 2 - Percentual de erros no $1^{\circ}$ ano

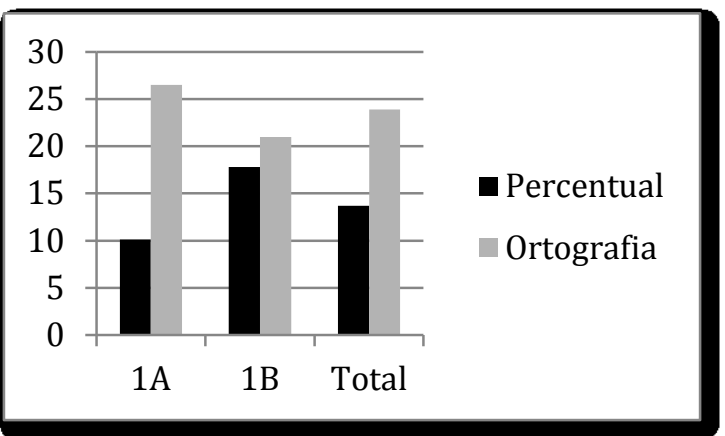

Gráfico 3 - Percentual de não respostas no $1^{\circ}$ ano

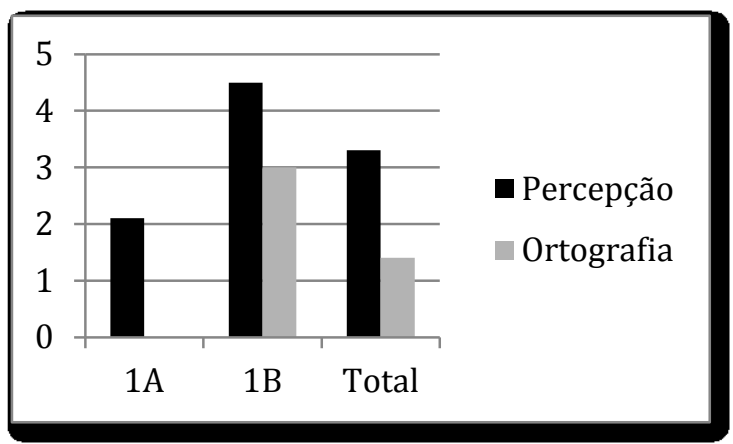


Gráfico 4 - Percentual de respostas não interpretáveis no $1^{\circ}$ ano

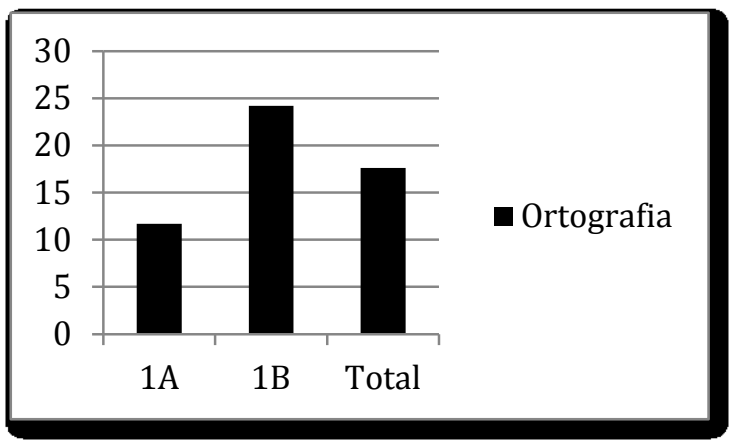

Com base nos resultados expostos nos gráficos 1-4, é possível observar, no $1^{\circ}$ ano do Ensino Fundamental, maior índice de acertos no desempenho perceptual-auditivo do que no desempenho ortográfico, e maior índice de erros no desempenho ortográfico do que no desempenho perceptual-auditivo. Em relação a não respostas, identificamos um número maior no desempenho perceptual-auditivo. Como dissemos anteriormente, para analisar a ortografia acrescentamos como critério as respostas não interpretáveis, já que, como destacamos, não seria possível desprezar o número desses dados.

Passamos para o detalhamento dos resultados do $2^{\circ}$ ano.

Gráfico 5 - Percentual de acertos no $2^{\circ}$ ano

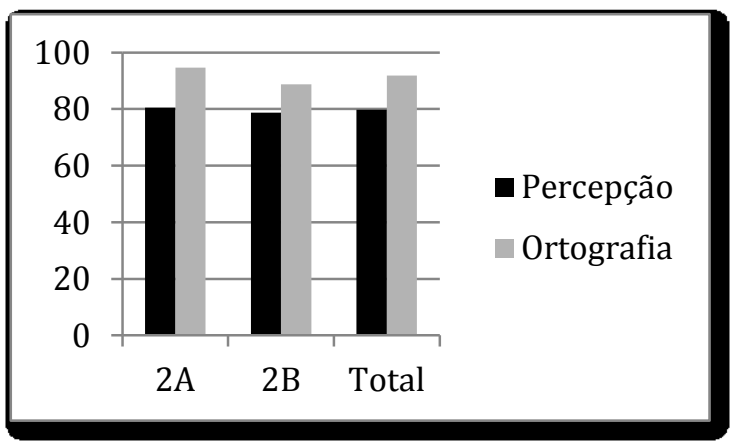


Gráfico 6 - Percentual de erros no $2^{\circ}$ ano

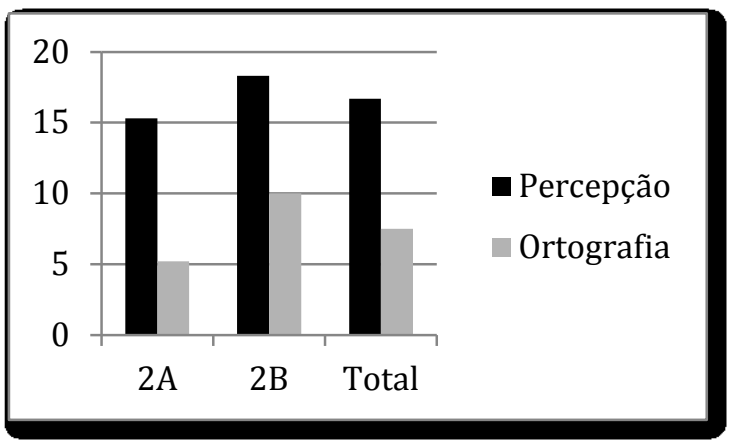

Gráfico 7 - Percentual de não respostas no $2^{\circ}$ ano

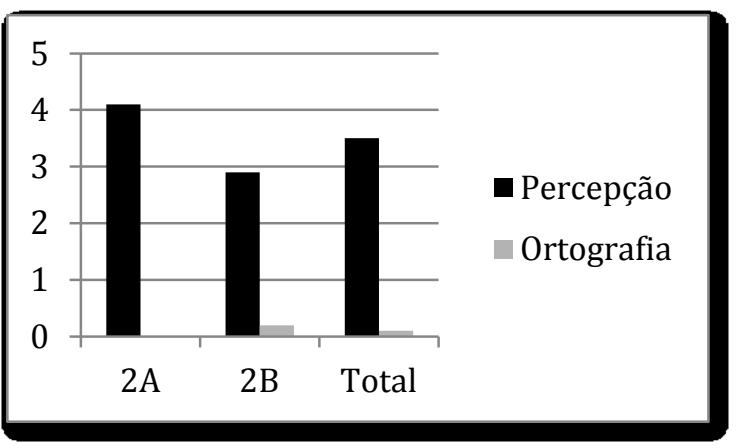

Gráfico 8 - Percentual de respostas não interpretáveis no $2^{\circ}$ ano

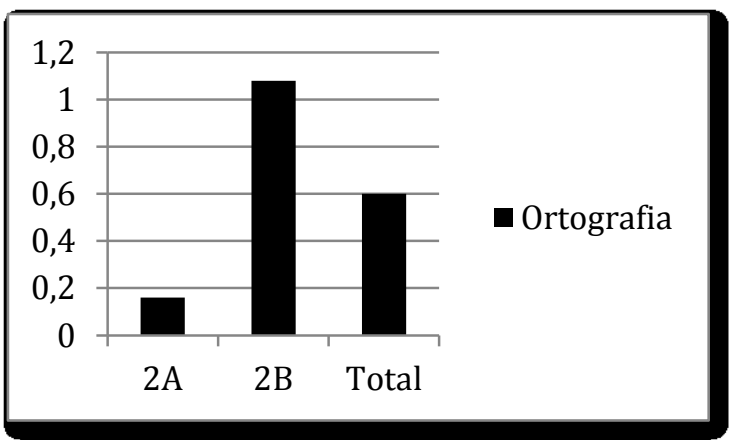


Com base nos gráficos 5-8, é possível observar, no $2^{\circ}$ ano do Ensino Fundamental, maior índice de acertos no desempenho ortográfico do que no desempenho perceptual-auditivo, e maior índice de erros no desempenho perceptual-auditivo do que no desempenho ortográfico. Em relação a não respostas, vemos um número maior no desempenho perceptual-auditivo. Podemos observar, ainda, um pequeno percentual de respostas não interpretáveis na ortografia no $2^{\circ}$ ano.

Comparando-se os grupos de crianças do $1^{\circ}$ e do $2^{\circ}$ ano, é possível detectarmos as seguintes tendências:

a) inversão das modalidades de erros, já que as crianças do primeiro ano mostram maior quantidade deles na tarefa de ortografia do que na tarefa de percepção-auditiva e, nas do segundo ano, verifica-se o contrário;

b) redução brusca de não respostas na tarefa ortográfica e de manutenção delas na tarefa de percepção-auditiva;

c) grande diminuição de respostas ortográficas não interpretáveis das crianças do primeiro para o segundo ano.

Com relação ao nosso segundo objetivo, mostraremos, nas tabelas 25, os resultados a que chegamos nas duas tarefas: de percepção-auditiva e de ortografia. Nessas tabelas, os números em cada célula correspondem à quantidade de vezes que uma consoante foi confundida com outra. $\mathrm{Na}$ primeira coluna, são expostas as consoantes testadas. Nas demais, com exceção da última, é exposta, individualmente, cada possibilidade de confusão (no interior das soantes) da consoante testada. Por fim, na última coluna, é mostrada a quantidade total de confusões. A título de exemplo, na terceira linha da primeira coluna da Tabela 2, vejamos o que se passou com a consoante $/ \mathrm{n} /$. Ao acompanharmos seu comportamento ao longo da linha, veremos que ela foi confundida 9 vezes com $/ \mathrm{m} /, 15$ vezes com $/ \mathrm{n} /, 7$ vezes com $/ 1 /, 4$ vezes com $/ K /$ e 6 vezes com $/ \mathrm{r} /$. Veremos, também, na última coluna dessa linha, que a consoante $/ \mathrm{n} /$ teve um total geral de 41 confusões.

Para responder a esse objetivo, foram analisados apenas os erros ortográficos entre elementos da grande classe das soantes. Além da exclusão dos dados de omissões ortográficas e dos dados não interpretáveis, foram, ainda, desconsiderados os erros que envolveram substituições entre grafemas que remetiam a fonemas de outras classes que não a das soantes. 
Para melhor observarmos os contrastes mais facilmente e mais dificilmente percebidos e registrados pelas crianças, apresentaremos os resultados de cada série escolar individualmente.

Tabela 2 - Percepção-auditiva do contraste de soantes em crianças do $1^{\circ}$ ano

\begin{tabular}{lrrrrrrr}
\hline & $/ \mathbf{m} /$ & $/ \mathbf{n} /$ & $/ \mathbf{n} /$ & $/ \mathbf{l} /$ & $/ \mathbf{K} /$ & $/ \mathbf{r} /$ & Total \\
\hline$/ \mathbf{m} /$ & - & 15 & 6 & 6 & 4 & 8 & 39 \\
$/ \mathbf{n} /$ & 9 & - & 15 & 7 & 4 & 6 & 41 \\
$/ \mathbf{n} /$ & 6 & 13 & - & 15 & 4 & 8 & 46 \\
$/ \mathbf{l} /$ & 7 & 10 & 7 & - & 5 & 6 & 35 \\
$/ \mathbf{K} /$ & 9 & 7 & 9 & 4 & - & 3 & 32 \\
$/ \mathbf{f} /$ & 6 & 4 & 4 & 6 & 3 & - & 23 \\
\hline Total & 37 & 49 & 41 & 38 & 20 & 31 & 216 \\
\hline
\end{tabular}

Tabela 3 - Ortografia de contrastes entre as soantes em crianças do $1^{\circ}$ ano

\begin{tabular}{lrrrrrrrr}
\hline & M & N & NH & L & LH & LI & R & Total \\
\hline M & - & 12 & 0 & 0 & 0 & 0 & 1 & 13 \\
N & 4 & - & 0 & 5 & 5 & 0 & 6 & 19 \\
NH & 2 & 13 & - & 3 & 18 & 1 & 3 & 40 \\
L & 0 & 2 & 0 & - & 3 & 0 & 3 & 8 \\
LH & 0 & 4 & 4 & 31 & - & 23 & 3 & 65 \\
$\mathbf{R}$ & 1 & 0 & 0 & 24 & 6 & 0 & - & 31 \\
\hline Total & 7 & 31 & 4 & 62 & 32 & 24 & 16 & 176 \\
\hline
\end{tabular}

Tabela 4 - Percepção-auditiva do contraste de soantes em crianças do $2^{\circ}$ ano

\begin{tabular}{lrrrrrrr}
\hline & $/ \mathbf{m} /$ & $/ \mathbf{n} /$ & $/ \mathbf{n} /$ & $/ \mathbf{l} /$ & $/ \mathbf{L} /$ & $/ \mathbf{r} /$ & Total \\
\hline$/ \mathbf{m} /$ & - & 20 & 15 & 13 & 8 & 10 & 72 \\
$/ \mathbf{n} /$ & 10 & - & 13 & 12 & 8 & 3 & 50 \\
$/ \mathbf{n} /$ & 5 & 9 & - & 13 & 6 & 8 & 45 \\
$/ / /$ & 2 & 12 & 6 & - & 6 & 12 & 45 \\
$/ \mathbf{L} /$ & 5 & 2 & 6 & 3 & - & 8 & 26 \\
$/ \mathbf{r} /$ & 6 & 2 & 2 & 4 & 5 & - & 19 \\
\hline Total & 30 & 53 & 47 & 47 & 37 & 43 & 257 \\
\hline
\end{tabular}

Tabela 5 - Ortografia de contrastes entre as soantes em crianças do $2^{\circ}$ ano

\begin{tabular}{lrrrrrrrr}
\hline & M & N & NH & L & LH & LI & R & Total \\
\hline $\mathbf{M}$ & - & 3 & 1 & 0 & 0 & 0 & 0 & 4 \\
$\mathbf{N}$ & 4 & - & 0 & 1 & 0 & 0 & 0 & 5 \\
NH & 3 & 2 & - & 0 & 0 & 0 & 0 & 5 \\
L & 0 & 0 & 0 & - & 1 & 0 & 1 & 2 \\
LH & 0 & 0 & 1 & 21 & - & 18 & 7 & 47 \\
$\mathbf{R}$ & 1 & 0 & 0 & 4 & 0 & 0 & - & 5 \\
\hline Total & 8 & 5 & 2 & 26 & 1 & 18 & 8 & 68 \\
\hline
\end{tabular}


Em busca de tendências para as quais esses números podem apontar, dividimos a grande classe das soantes em duas subclasses - nasais e líquidas - e categorizamos os erros das crianças de acordo com essas subclasses, como mostraremos nas tabelas 6-7, a seguir:

Tabela 6 - Percentual de erros de percepção-auditiva conforme subclasses

\begin{tabular}{lrr}
\hline Ano & Nasais & Líquidas \\
\hline $\mathbf{1}^{\mathbf{0}}$ ano & 59 & 41 \\
$\mathbf{2}^{\mathbf{o}}$ ano & 65 & 35 \\
\hline
\end{tabular}

Tabela 7 - Percentual de erros de ortografia de acordo com as subclasses

\begin{tabular}{lrr}
\hline Ano & Nasais & Líquidas \\
\hline $\mathbf{1}^{\mathbf{0}}$ ano & 41 & 59 \\
$\mathbf{2}^{\mathbf{0}}$ ano & 29 & 71 \\
\hline
\end{tabular}

Comparando-se os grupos de crianças do $1^{\circ}$ e do $2^{\circ}$ ano em relação a seus erros, levando-se em consideração a divisão das soantes em nasais e líquidas, é possível detectarmos as seguintes tendências:

a) relação entre as modalidades de tarefa e os tipos de erros, já que, na tarefa de percepção-auditiva, as crianças dos dois grupos mostraram maior quantidade deles nas nasais e, na tarefa de ortografia, nas líquidas;

b) percentual maior de erros de nasais na tarefa de percepçãoauditiva em ambos os grupos, porém mais acentuado nas crianças do $2^{\circ}$ ano;

c) percentual maior de erros de líquidas na tarefa de ortografia em ambos os grupos, porém mais acentuado nas crianças do $2^{\circ}$ ano.

\section{DISCUSSÃO DOS RESULTADOS}

Passemos à discussão das tendências detectadas nos resultados relativos ao primeiro objetivo da presente pesquisa.

Relembremos a primeira tendência, a inversão das modalidades de erros. Como vimos, as crianças do primeiro ano mostraram maior quantidade deles na tarefa de ortografia (do que na tarefa de percepçãoauditiva) e, nas do segundo ano, verificou-se o contrário. 
Observam-se, nessa inversão de tendências, diferentes maneiras com que as crianças dão indícios de sua inserção em práticas de oralidade e de letramento. Por um lado, detecta-se, nas crianças do primeiro ano, efeito maior de sua inserção em práticas de oralidade, na medida em que são melhores os seus resultados na tarefa auditiva e piores na tarefa ortográfica. Por outro lado, detecta-se, nas crianças do segundo ano, efeito maior de sua inserção em práticas de letramento. Esse efeito maior se pode detectar não apenas na diminuição dos erros na tarefa de ortografia, mas, sobretudo - e surpreendentemente - no aumento deles na tarefa auditiva. Essa inversão de tendências aponta, pois, para a complexidade da aquisição da percepçãoauditiva, uma vez que, além de confirmar resultados de estudos que atribuem a esse tipo de aquisição caráter gradiente - como, por exemplo, Shvachkin (1973), Pater, Stager e Werker (2004), Schier (2012), Schier, Berti e Chacon (2013) -, sugere que essa aquisição é afetada (uma vez que desestabilizada) pelo aumento da escolarização.

Essa nossa interpretação pode ser reforçada pela segunda tendência que identificamos nos resultados referentes ao primeiro objetivo deste estudo. Conforme os números expostos na Tabela 1, embora tenha havido redução brusca da quantidade de não respostas na tarefa ortográfica (de 18, no primeiro ano, para 1 , no segundo ano), sua quantidade na tarefa de percepção-auditiva se manteve praticamente igual (52, no primeiro ano e 51 no segundo ano). Como se vê, além de aumentarem os erros na tarefa auditiva com o aumento da escolaridade, mantiveram-se os números de não respostas nessa mesma tarefa, diferentemente do que ocorreu com a tarefa ortográfica.

Outro fator que sugere que a inserção em práticas de letramento afeta a aquisição da percepção-auditiva é o de que, embora os desempenhos nas tarefas de percepção e de ortografia tendam a se estabilizar de maneira gradual, essa estabilização ocorre de maneira mais lenta no desempenho perceptual-auditivo. Estudos posteriores e mais diretamente voltados para essa questão deverão ser realizados para ser confirmada, ou não, a interpretação que fazemos de que não apenas a ortografia sofre efeitos da inserção das crianças em práticas de letramento, mas, também, o próprio modo como as crianças interpretam, auditivamente, características acústicas dos segmentos da fala. 
Há, porém, que se fazer uma ressalva. As práticas pedagógicas, durante a alfabetização, voltam-se preferencialmente (ou quase que totalmente) para as questões ortográficas - e a última tendência mostrada pelos resultados referentes ao primeiro objetivo deste estudo (a da grande diminuição de respostas ortográficas não interpretáveis das crianças do primeiro para o segundo ano) indicia efeitos dessa preferência, tal como também observa Schier (2012) em sua investigação sobre a relação entre a aquisição da percepção-auditiva e a aquisição da ortografia de consoantes fricativas. Mas pouca ou nenhuma atenção é dada às características auditivas da fala nas práticas pedagógicas. Portanto, a estabilização mais lenta no desempenho perceptual-auditivo pode ser creditada (também) à ausência de práticas específicas com a audição, diferentemente do que ocorre com a ortografia.

Passemos à discussão das tendências que detectamos nos resultados relativos ao segundo objetivo da presente pesquisa. Relembremos a primeira tendência, a saber, a da relação entre as modalidades de tarefa e os tipos de erros. Na tarefa de percepção-auditiva, conforme nos mostram os percentuais expostos na tabela 6, o maior percentual de erros das crianças de ambos os grupos foi verificado nas consoantes nasais - 59\% e $65 \%$, respectivamente. Já na tarefa de ortografia, de acordo com percentuais expostos na tabela 7, são as líquidas que provocam maior percentual de erros $-59 \%$ e $71 \%$, respectivamente.

Características acústicas das consoantes nasais podem explicar essa inversão. Com efeito, nesse grupo de consoantes, a presença de antiformantes em sua configuração provoca absorção seletiva de energia acústica. Os efeitos espectrais de antiformantes são opostos aos dos formantes, já que a presença de um antiformante causa uma absorção seletiva de energia acústica tanto em uma frequência mais específica quanto em sua vizinhança, devido à ressonância característica de um subsistema como o da cavidade nasal (FUJIMURA; ERICKSON, 1995). Essa absorção de energia pode ser, portanto, um fator que dificulta a percepção-auditiva das consoantes nasais - fato para o qual já chamaram a atenção Chacon e Berti (2006) -, sem consequências mais diretas para sua ortografia. 
Já com relação à maior quantidade de erros em líquidas na tarefa de ortografia, uma observação de fundamental importância deve ser feita: de um total de 158 erros ortográficos nessa subclasse das soantes, 112 (70,88\%) envolveram o dígrafo LH. Esse dígrafo foi, preferencialmente, substituído por L em 52 casos $(46,42 \%$ de 112$)$, e por LI em 41 casos (36,60\% de 112), como mostram os exemplos das Figuras 1 e 2:

Figura 1.

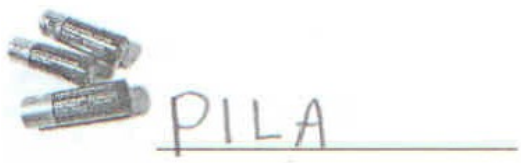

Figura 2.

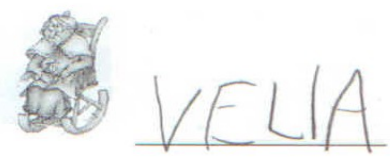

Esse predomínio sugere que o que mais está em questão nos erros ortográficos de líquidas seja a dificuldade que o grupo de crianças mostra de lidar com a correspondência entre duas unidades gráficas e um único fonema. O grupo tende, então, a resolver essa complexidade ou pelo apagamento da letra $\mathrm{H}$ do dígrafo (fato que faz corresponder a sílaba ortográfica resultante desse apagamento à sílaba canônica universal CV), ou pela busca de uma correspondência termo a termo entre a ortografia e a percepção da palatalização de $[K]$ como decorrente de uma sequência fonética [li].

Essa tendência se mostra forte na medida em que se pode detectá-la também nos erros ortográficos de nasais. Com efeito, de um total de 86 desses erros, $45(52,32 \%)$ deles envolveram o dígrafo $\mathrm{NH}$, que, ou sofreu apagamento de $\mathrm{H}$ semelhante ao verificado em LH em 15 ocorrências (33,33\%), ou foi substituído pelo dígrafo LH em 18 ocorrências (40\%), como mostramos nos exemplos das Figuras 3 e 4 :

Figura 3.

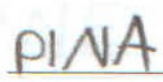

Figura 4.

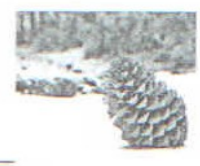

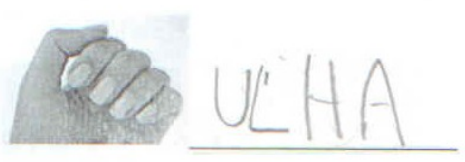


Um fato interessante a ser notado é o da direção da substituição entre dígrafos. O dígrafo $\mathrm{NH}$ teve $40 \%$ (18 em 45) de substituição por LH, mas a substituição na tendência inversa foi de apenas 4,46\% (5 em 112). Embora em termos ortográficos se trate de processos semelhantes (dois dígrafos marcados por $\mathrm{H}$ na segunda posição em correspondência com fonemas palatais), a direção preferencial da substituição em favor da palatal líquida reforça a ação dos aspectos perceptuais-auditivos, já que, como apontamos acima, a percepção das nasais é dificultada pela absorção de energia acústica causada pela presença de antiformantes em sua configuração.

Passemos para a discussão da segunda tendência detectada nos resultados a que chegamos na investigação do segundo objetivo que orienta este estudo. Relembrando-a: embora o percentual de erros de percepçãoauditiva nas crianças de ambos os grupos tenha sido maior entre as nasais do que entre as líquidas, a diferença percentual se acentuou nas crianças do $2^{\circ}$ ano.

A acentuação da diferença no $2^{\circ}$ ano reforça nossa hipótese de que a alfabetização provoca desajustes na aquisição da percepção-auditiva. No entanto, o desajuste pode ser maior ou menor quando se observam as características das duas subclasses das soantes - as nasais e as líquidas. Com efeito, ele se mostra mais acentuado na percepção das nasais do que na das líquidas (fato que, como vimos, também se explica pela diminuição de energia acústica em sua produção). Desse modo, nossos resultados sugerem não apenas gradiência e desajustes na aquisição da percepçãoauditiva de soantes, mas, principalmente, gradiência na percepção das diferentes subclasses no interior dessa grande classe - questão que, ela também, merece investigações mais aprofundadas e com maior número de sujeitos.

Relembremos, por fim, a última tendência detectada em resultados relativos ao segundo objetivo deste estudo, a saber: embora o percentual de erros de ortografia nas crianças de ambos os grupos tenha sido maior entre as líquidas do que entre as nasais, a diferença percentual se acentuou nas crianças do $2^{\circ}$ ano.

Um fato bastante pontual mascara essa acentuação de diferença percentual. Como vimos na Tabela 3 e na Tabela 5, embora a dificuldade 
nas duas diferentes séries envolva preferencialmente o dígrafo $\mathrm{LH}$, na primeira série essa dificuldade envolve mais os outros membros dessa subclasse $(37,5 \%$ - 39 de 104 erros) do que se observa na segunda série (12,7 - 7 em 54 erros). Desse modo, ainda que, da primeira para a segunda série, o percentual de erros em líquidas aumente, esses erros, na verdade, mostram-se concentrados em um único elemento dessa subclasse das soantes, o dígrafo LH $(87,3 \%$ - 47 em 54 erros $)$ - fato que aponta para o sucesso, na tarefa de ortografia, das práticas de alfabetização nas crianças do segundo ano.

\section{CONSIDERAÇÕES FINAIS}

$\mathrm{Na}$ Introdução deste artigo, manifestamos a expectativa de que os resultados a que chegássemos pudessem contribuir teoricamente para o aprofundamento da compreensão sobre as relações entre a aquisição da percepção-auditiva e a aquisição da ortografia. Mesmo que iniciais, nossos resultados já permitem entrever três grandes tendências no estabelecimento dessas relações.

No que se refere à primeira direção, conforme vimos, nossos resultados confirmam estudos que postulam um caráter gradual da aquisição da percepção. Mas, além dessa confirmação, nossos resultados sugerem, ainda, gradiência na aquisição de subclasses no interior de uma grande classe: com efeito, o percentual de desajustes na identificação auditiva de soantes variou de acordo com a natureza da subclasse envolvida nessa grande classe - maior em nasais do que em líquidas.

Já que no que se refere à segunda direção, nossos resultados sugerem relações não diretas entre a aquisição da percepção e a aquisição da ortografia de consoantes soantes. Embora tenham se mostrado, em grande medida, relacionados - já que tanto na percepção quanto na ortografia majoritariamente os erros ocorreram no interior dessa grande classe -, eles apontaram, também, para não correspondências entre os dois tipos de tarefa quando se levou em conta a divisão da grande classe das soantes subclasses de nasais e líquidas. 
Por fim, no que se refere à terceira direção, nossos resultados apontam para uma questão de central importância, não levantada ou investigada nos trabalhos a que tivemos acesso sobre a aquisição da percepção-auditiva: aquela do papel que as práticas de letramento (especialmente aquelas que dizem respeito à alfabetização) desempenham não apenas no que diz respeito à aquisição da ortografia, mas, também, no que diz respeito à própria maneira como os segmentos da grande classe das soantes passam a ser percebidos com o avanço da alfabetização.

Temos, pois, esboçadas três direções para investigações posteriores e mais aprofundadas sobre as relações entre a aquisição da percepçãoauditiva e a aquisição da ortografia.

\section{REFERÊNCIAS}

ABAURRE, M. B. M. Introduzindo a questão dos aspectos lingüísticos da alfabetização. Revista da ABRALIN, Curitiba, v. 7, p. 29-36, 1986.

. O que revelam os textos espontâneos sobre a representação que faz a criança do objeto escrito?. In: KATO, M. (Org.). A concepção da escrita pela criança. 2. ed. Campinas: Pontes Editores, 1988, v. 1, p. 135-142.

. A alfabetização na perspectiva da lingüística: contribuições teóricometodológicas. Cadernos ANPED, Belo Horizonte, v. 6, p. 91-124, 1994.

. Horizontes e limites de um programa de investigação em aquisição da escrita. In: LAMPRECHT, R. (Org.) Aquisição da Linguagem: questões e análises. Porto Alegre: EDIPUCRS, 1999. p. 167-186.

. Dados da escrita inicial: indícios de construção da hierarquia de constituintes silábicos? In: HERNANDORENA, C. L. M. (Org.) Aquisição de língua materna e de língua estrangeira: aspectos fonético-fonológicos. Pelotas: EDUCAT/ ALAB, 2001, v. 1, p. 63-85.

ABAURRE, M. B. M.; CAGLIARI, L. C.; MAGAlHÃES, M. A. C. C.; LIMA, S. C. Leitura e escrita na vida e na escola. Leitura: teoria e prática, Porto Alegre, v. 4, n. 6, p. 15-26, 1985.

ABAURRE, M. B. M.; ABAURRE, M. L. M. A avaliação objetiva de produções escritas. Ciências e Letras, Porto Alegre, v. 26, p. 141-159, 1999.

ADAMOLI, M. A.; MIRANDA, A. R. M. Do conhecimento fonológico ao conhecimento ortográfico: as diferentes grafias dos ditongos orais mediais ai e ei em textos de escrita inicial. Cadernos de Pesquisas em Linguística, Porto Alegre, v. 4, p. 232-255, 2009. 
AMARAL, A. S. do; FREITAS, M. C. C. de; CHACON, L.; RODRIGUES, L. L. Omissão de grafemas e características da sílaba na escrita infantil. Revista CEFAC, São Paulo, v. 13, p. 846-855, 2011.

ANDRÉ C., GHIO A., CAVÉ C., TESTON B. PERCEVAL: PERCeption EVALuation Auditive \& Visuelle (Versão 5.0.30) [Programa de computador]. Compilado de $<$ http://aune.lpl.univ-aix.fr/ lpldev/perceval/> em janeiro de 2009.

BARCELLOS, C. A. P.; FREIRE, R. M. Assessoria fonoaudiológica na escola: sob o efeito da escrita e sua aquisição. Revista Distúrbios da Comunicação, São Paulo, v. 17, n. 3, p. 373-383, 2005.

BERTI, L. C. PERCEFAL: Instrumento de percepção de fala. In: I Simpósio Internacional do Grupo de Pesquisa "Avaliação da Fala e da Linguagem" Perspectivas Interdisciplinares em Fonoaudiologia; Set 29-Out 01; Marília, 2011. BERTI, L. C.; CHACON, L.; SANTOS, A. P. A escrita de /aN/ por pré-escolares: pistas acústico-auditivas. Cadernos de Educação, Pelotas, v. 19, p. 195-291, 2010. BOERSMAN, P. WEENINK, D. Praat: doing phonetics by computer (Version 5.0.30) Available from: <http://www.praat.org/> (Nov 2009).

CAGLIARI, L. C. A ortografia na escola e na vida. Projeto Ipê Curso II, São Paulo, p. 97-108, 1986.

. O segredo da alfabetização. Jornal da Alfabetizadora, Porto Alegre, v. 4, n. 20, p. 9-11, 1992.

. Sobre a didática da alfabetização. Jornal do Alfabetizador, Porto Alegre, v. IX, n. 54, p. 10-11, 1998.

. Conhecimentos técnicos para alfabetizar. Línguas \& Letras, Cascavel, v. 2, n. 1, p. 73-84, 2001. $\overline{58,2002}$.

. Alfabetização e ortografia. Educar em Revista, Curitiba, v. 20, n. 1, p. 432004.

. Lingüística e alfabetização. Espaço (INES), Brasília, n. 20, p. 46-52,

CAMPOS, P. B. B.; TENANI, L. E.; BERTI, L. C. Os registros não-convencionais da coda nasal em dados de EJA. Estudos Linguísticos, São Paulo, v. 40, p. 524538, 2011.

CAPRISTANO, C. C. A propósito da escrita infantil: uma reflexão sobre as segmentações não-convencionais. Letras de Hoje, Porto Alegre, v. 39, n.3, p. 245 260, 2004.

. Continuidades e descontinuidades em direção à palavra escrita convencional. Anais do Seta, Campinas, v. 1, p. 55-65, 2007. 
. Por uma concepção heterogêanea da escrita que se produz e que se ensina na escola. Cadernos de Educação, Pelotas, v. 1, p. 171-193, 2010.

CARDOSO, M. H.; RODRIGUES, L. L.; FREITAS, M. C. C. de; CHACON, L. A complexidade da coda silábica na escrita de pré-escolares. Distúrbios da Comunicação, São Paulo, v. 22, p. 213-221, 2010.

CHACON, L. Algumas palavras sobre a aquisição da pontuação. In:

LAMPRECHT, R. R. (Org.). Aquisição da linguagem: questões e análises - v. 1. Porto Alegre: Editora da PUCRS, 1999. p. 187-200.

. Constituintes prosódicos e letramento em segmentações nãoconvencionais. Letras de Hoje, Porto Alegre, v. 39, n.3, p. 223-232, 2004a.

. Oralidade e letramento na construção da pontuação. Revista Letras, Curitiba, Curitiba, v. 61, n. Especial, p. 97-122, 2004b.

. Hipersegmentações na escrita infantil: entrelaçamentos de práticas de oralidade e de letramento. Estudos Linguísticos, Campinas, v. 34, p.77-86, 2005.

. Prosodia y cultura letrada en hipersegmentaciones: reflexiones sobre la adquisición de la noción de palabra. Lenguas Vivas, Madrid, v. VI, p. 48-59, 2006.

. Para além de vínculos diretos entre características fonético-segmentais e ortográficas na escrita infantil. Revista de Estudos da Linguagem, Belo Horizonte, v. 16 , p. 215-230, 2008.

CHACON, L.; BERTI, L. C. Ocorrências de coda silábica simples na escrita infantil. In: MATZENAUER, C. L.; MIRANDA, A. R. M.; FINGER; AMARAL, L. I. C. (Orgs.). Estudos da linguagem - VII Círculo de Estudos Linguísticos do Sul. 1. ed. Pelotas: EDUCAT, 2008. v. Único, p. 273-289.

CHACON, L.; BERTI, L. C.; BURGEMEISTER, A. Ortografia da nasalidade em ataque e coda silábica na escrita infantil: características fonéticas e fonológicas. Verba Volant, Pelotas, v. 2, p. 1-21, 2011.

CUNHA, A. P. N. A influência dos constituintes prosódicos na aquisição da língua escrita. Caderno de Letras, Pelotas, v. 1, n.10, p. 14-23, 2004.

. As segmentações não-convencionais da escrita e sua relação com os constituintes prosódicos. Cadernos de Educação, Pelotas, v. 35, p. 323-358, 2010. CUNHA, A. P. N.; MIRANDA, A. R. M. A influência da hierarquia prosódica em hipossegmentações da escrita de crianças de séries iniciais. Revista Virtual de Estudos da Linguagem, Porto Alegre, v. 5, p. 1-19, 2007.

. A hipo e a hipersegmentação em dados de aquisição de escrita: a influência da prosódia. Alfa: Revista de Linguística, São José do Rio Preto, v. 53, n. 1, p. 127-148, 2009.

FERREIRA, C. R. G. As hipersegmentações como marcas de um sistema em construção na escrita inicial de crianças e alunos de EJA. In: MERÇALO, M. J.; 
LIMA-HERNANDES, M. C. L. (Orgs.). Língua Portuguesa: ultrapassar fronteiras, juntar culturas. Évora: Universidade de Évora, 2010. p. 1-14.

FUJIMURA, O.; ERICKSON, D. Acoustic phonetics. In: HARDCASTLE, W. J.; LAVER, J. (Eds.). The Handbook of Phonetic Sciences. Oxford: Blackwell, 1995. p. 65-115.

KOMESU, F. C.; TENANI, L. E. A relação fala-escrita em dados produzidos em contexto digital. Scripta, Belo Horizonte, v. 13, p. 203-217, 2010.

KRISTENSEN, C. R.; FREIRE, R. M. Interpretação da escrita infantil: a questão da autoria. Revista Distúrbios da Comunicação, São Paulo, v. 13, n. 1, p. 19-47, 2001.

MASSI, G. A. Dislexia ou processo de aquisição de escrita? Revista Distúrbios da Comunicação, São Paulo, v. 16, n. 3, p. 355-369, 2004.

MASSI, G. A.; GUARINELLO, A. C.; BERBERIAN, A. P.; SANTANA, A. P.; SCHEMBERG; S.; SOUZA, C. Indícios do processo de apropriação da escrita versus sintomas disléxicos. Revista Distúrbios da Comunicação, São Paulo, v. 20, n. 3, p. 327-338, 2008.

MILLER, G. A.; NICELY, P .E. An analysis of perceptual confusions among some English consonants. Journal of the Acoustical Society of America, New York, v. 27, p. 338-352, 1955.

MIRANDA, A. R. M. A aquisição ortográfica das vogais do português - relações com a fonologia e a morfologia. Letras, Santa Maria, v. 36, p. 151-168, 2008.

MIRANDA, A. R. M.; MATZENAUER, C. L. B. Aquisição da fala e da escrita: relações com a fonologia. Cadernos de Educação, Pelotas, v. 35, p. 359-405, 2010. MIRANDA, A. R. M.; SILVA, M. R. da; MEDINA, S. Z. O sistema ortográfico do português brasileiro e sua aquisição. Linguagens \& Cidadania, Santa Maria, v. 14, p. 1-15, 2005.

MOTA, H. B. Pares mínimos: os contrastes do português brasileiro. Pró Fono Revista de Atualização Científica, Barueri, v.13, n. 1, p. 98-106, 2001.

NESPOR, M; VOGEL, I. Prosodic phonology. Dordrecht: Foris Publications, 1986.

PATER, J.; STAGER, C.; WERKER, J. F. The perceptual acquisition of phonological contrasts. Language, Washington, v. 80, p. 361-379, 2004.

PERROTTA, C. Breve estudo de caso: uma abordagem da escrita na terapia fonoaudiológica. Revista Distúrbios da Comunicação, São Paulo, v.14, n.1, p. 91102, 2002.

SCHIER, A. C. Percepção de fala e ortografia na escrita de crianças do ensino fundamental. 2012, 55f. Dissertação (Mestrado em Fonoaudiologia) - Faculdade de Filosofia e Ciências, Universidade Estadual Paulista "Júlio de Mesquita Filho", Marília, 2012. 
SCHIER, A. C.; BERTI, L. C.; CHACON, L. Desempenho perceptual-auditivo e ortográfico de consoantes fricativas na aquisição da escrita. CoDAS, v. 25, n. 1, p. 45-51, 2013.

SERRA, M. P.; TENANI, L. E.; CHACON, L. Reelaboração da segmentação: um olhar para a escrita infantil. Estudos linguísticos, São Paulo, v. XXXV, p. 12471254, 2006.

SHVACHKIN, N. K. The development of phonemic speech perception in early childhood. In: FERGUSON C.A; SLOBIN D. I. Studies of Child Language Development. New York: Holt, Rinehart, and Winston, 1973. p. 91-127.

SONCIN, G. C. N. Os usos da vírgula em textos de alunos da última série do Ensino Fundamental. Mosaico, São José do Rio Preto, v. 1, p. 73-87, 2010.

TEIXEIRA, S. de M.; DEVANTIER, N.; GRASSI, L. H.; MIRANDA, A. R. M.. Uma reflexão acerca do erro ortográfico: a importância do conhecimento sobre a língua para a prática pedagógica de professores das séries iniciais. Verba Volant, Pelotas, v. 2, p. 78-94, 2011.

TENANI, L. E. Segmentações não-convencionais e teorias fonológicas. Letras de Hoje, Porto Alegre, v. 39, n.3, p. 233-244, 2004.

. Notas sobre a relação entre constituintes prosódicos e ortografia. Revista de Estudos da Linguagem, Belo Horizonte, v. 16, p. 231-245, 2008.

. A grafia dos erros de segmentação não-convencional de palavras.

Cadernos de Educação, Pelotas, v. 35, p. 247-269, 2010.

TENANI, L. E.; PARANHOS, F. C. Análise prosódica de segmentações nãoconvecionais de palavras em textos do sexto ano do Ensino Fundamental. Filologia e Linguística Portuguesa, São Paulo, v. 13, p. 477-504, 2011.

TENANI, L. E.; REIS, M. C. . "E veveram felizes para sempre": análise de grafias não-convencionais de vogais pretônicas. Verba Volant, Pelotas, v. 2, p. 22-43, 2011.

VAZ, S. Percepção de fala e aquisição da escrita de sonorantes. Relatório FAPESP de Iniciação Científica, Processo 11/22873-0, Universidade Estadual Paulista Júlio de Mesquita Filho, Marília, 2012.

\section{Recebido em: 04/06/13. Aprovado em: 03/12/13.}

Title: Relationships between acquisition of auditory perception and orthography learning: sonorant consonants under discussion Author: Lourenço Chacon; Suellen Vaz Abstract: We compared the relationships between acquisition of auditory perception and the acquisition of sonorant consonants spelling in children of the first two grades of elementary school. The 
comparison was based on a procedure of identifying and writing the same set of words that presented phonological contrasts between them. As to the results, it was found: (1) gradation in the acquisition of subclasses within a larger class; (2) matches and mismatches between the two types of task; (3) increased adjustments in spelling and more mismatches in auditory perception with increasing enrollment. This set of results indicates, therefore, the complexity of the relationships between the acquisition of auditory perception and the acquisition of spelling, since, once contacted, their journey together at the same time promotes links and outcomes between them.

Keywords: Writing acquisition. Auditory perception. Spelling.

Título: Relaciones entre adquisición de la percepción auditiva y aprendizaje de la ortografía: consonantes sonoras en cuestión Autores: Lourenço Chacon; Suellen Vaz

Resumen: Fueron comparadas relaciones entre la adquisición de la percepción auditiva y la adquisición de la ortografía de consonantes sonoras en niños de los dos primeros grados de lo enseñanza primaria. La comparación fue basada en un procedimiento de identificación y de escritura de un mismo conjunto de palabras que presentaban contrastes fonológicos entre sí. En cuanto a los resultados, se verificó: (1) cierta graduación en la adquisición de subclases en el interior de una gran clase; (2) correspondencias y no correspondencias entre los dos tipos de tarea; (3) más ajustes en la ortografía y más desajustes en la percepción auditiva con el aumento de la escolarización. Ese conjunto de resultados apunta, por lo tanto, para la complejidad de las relaciones entre la adquisición de la percepción auditiva y la adquisición de la ortografia, ya que, una vez en contacto, su recorrido conjunto al mismo tiempo promueve enlaces y desenlaces entre ellas.

Palabras-clave: Adquisición de la escritura. Percepción auditiva. Ortografia. 